\title{
Comparative Study between Conventional Surgery, Endovenous Laser Ablation and Saphenofemoral Disconnection with Endovenous Chemical Ablation for Treatment of Lower Limbs Varicose Veins
}

\author{
Mohamed Ahmed Agena ${ }^{1, *}$ MSc, Walied Mohamed Khereba ${ }^{1}$ MD , Aymen Amen Mohy Elden ${ }^{1}$ MD
}

\section{*Corresponding Author: Mohamed Ahmed Agena dr.m.agena@gmail.com}

\section{Received for publication, 22-3-2020; Accepted, 5-6-2020; Published on line, 2020.}

\section{Copyright 2020 The Authors published by Al-Azhar University, Faculty of Medicine, Cairo, Egypt. All rights reserved. This an open-access article distributed under the legal terms, where it is permissible to download and share the work provided it is properly cited. The work cannot be changed in anyway or used commercially. \\ doi: 10.21608/aimj.2020.26256.1177 \\ ${ }^{1}$ Vascular surgery Department, Faculty of Medicine, Al-Azhar University, Damietta, Egypt}

\begin{abstract}
Background: Endovenous, open surgery or hybrid treatment are commonly performed methods of treatment for varicose veins. Comparative study between triple saphenectomy, Endovenous laser ablation (EVLA) and Endovenous Chemical Ablation with Trendelenburg's operation (eCAT) for treatment of primary varicose veins as regard, the return to daily activity, residual varicosities, complications, GSV caliber and, recurrence after one year.

Patient and methods: Seventy five patients with primary varicose veins presented at ALAzhar University hospital of New Damietta city during the period from November 2016 to December 2018. All patients were randomized into three equal groups each included 25 patients. Group I was treated by triple saphenectomy, group II was treated by EVLA, while group III was treated by eCAT.

Results: Return to daily activity was more rapid in group II than that of group I and group III. Statistically significant results had been detected in patients with group III as regard reduced incidence of saphenous nerve injury, residual varicosities, recurrence together with early ecchymosis and hematoma formation. Saphenous nerve injury had been detected in 5 and 2 patients for group I, II respectively but not in group III. Residual varicosities were detected in 10,15,5 patients for group I, II and III respectively.

Conclusion: Endovenous chemical ablation with Trendelenburg's operation had better results than endovenous laser ablation and triple saphenectomy as regard saphenous nerve injury, residual varicosities and recurrence with lower incidence of postoperative ecchymosis and hematoma formation.

Keywords: varicose veins; endovenous; chemical Ablations; laser ablation;

Trendelenburg's operation.
\end{abstract}

Disclosure: The authors have no financial interest to declare in relation to the content of this article. The Article Processing Charge was paid for by the authors.

Authorship: All authors have a substantial contributions to the article

\section{INTROUDTION}

Venous insufficiency at lower extremities may result in clinical problems from cosmetic issues to ulcerations. When the frequency of venous insufficiency and its related problems are considered besides their diversity, it is encountered as a public health issue. This pathology is reported to affect $40 \%$ of women and $20 \%$ of men.

Patients with varicose veins may complain of unsightly appearance, aching, heaviness, pruritus, and early fatigue of the affected leg. These symptoms worsen with prolonged standing and sitting and are relieved by elevation of the leg above the level of the heart. Also, mild edema is often present. More severe signs include thrombophlebitis, hyperpigmentation, lipodermatosclerosis, ulceration, and bleeding. ${ }^{2}$

Triple saphenectomy (saphenofemoral disconnection (SFD), stripping of great saphenous vein and stab avulsion) may be the preferred therapy for patients with the great saphenous vein (GSV) of very large diameter $(>2 \mathrm{~cm}){ }^{3}$

Endovenous laser Ablation (EVLA), is now widely accepted and recognized as the first-line treatment for truncal varicose veins. ${ }^{4-5}$ This approach enhanced recovery, with less pain, resulting in improvement in the life events when compared with surgical ligation with stripping, and improved efficacy when compared with the injection of foam sclerotherapy. However, (EVLA) carry the risk of soft tissue and/or nerve damage. Thus, patients are treated with (EVAL) require tumescent anaesthesia, which requires multiple injections around the length of the target vein. Some patients still experience weeks of post-operative pain ${ }^{4}$.

Other interventional management includes injection sclerotherapy, surgical therapy, or hybrid techniques. Injection sclerotherapy acts by destroying the venous endothelium that results in thrombosis and eventually fibrosis ${ }^{5}$.

Foam sclerotherapy allows enhanced contact with the vein wall on injection. Effective interaction with the vein wall may be encumbered by blood flow within larger veins that dissipates the agent ${ }^{6}$. Endovenous chemical ablation with trendelenburg's operation (e CAT) is a method for the treatment of varicose veins that started in December 2014 at Al-Azhar university hospital (New Damietta) by walied khereba and his team, saphenofemoral disconnection and ligation of all tributaries and endovenous Chemical Ablation of GSV were done at the same sitting.

\section{PATIENT AND METHODS}

This was a comparative study conducted on patients presented by primary varicose veins (VV) of the lower limb (LL) at AL-Azhar University hospital of New Damietta city during the period from November 2016 to December 2018. 


\section{Inclusion criteria}

Patients presented by primary VV of the LL complaining of Leg pain, cosmetic disfigurement, leg ulcer, itching, or pigmentation at LL. With the incompetence of the saphenofemoral junction (SFJ) and or saphenopopliteal junction (SPJ).

\section{Exclusion criteria}

Lower limb involvement by any of the following conditions; secondary VV, recurrent VV, lymphedema, acute superficial thrombophlebitis, arterio-venous fistula (congenital or acquired), congenital anomalies of the venous system, general comorbidities, skin infection or ischemia.

\section{Ethical consideration and randomization}

The Study protocol was approved by the Institution Research Board of the faculty of medicine, AL-Azhar University, New Damietta. Informed consent was obtained from all patients of the study. Confidentiality and personal privacy were respected at all levels of the study. Seventy-five patients were divided into 3 equal groups each had 25 patients. Randomization was achieved through sealed envelopes. Patients of Group (I) underwent triple saphenectomy, and patients of Group (II) underwent Endovenous laser ablation (ELA), while patients of Group (III)underwent Endovenous chemical ablation with Trendelenburg's operation (e CAT).

\section{Patient preparation}

Full history taking, laboratory, and radiological investigations (Duplex ultrasound of venous system of the lower limb with an assessment of great saphenous vein, small saphenous vein, and extra-axial varicosities (patency and diameters) were fulfilled for all patients preoperatively.

\section{Group (I): Triple saphenectomy}

The SFJ and its tributaries were approached through an oblique 2 $\mathrm{cm}$ incision.in the groin crease. The main trunk of GSV was identified. Each of the main tributaries was ligated and divided. High ligation of GSV was performed close to the femoral vein. Care was taken to avoid narrowing of the femoral vein and to avoid leaving a long stump

GSV stripping was the central component of the classic operation for varicose veins. This targeted approach to stripping leaves normal distal veins for potential future grafting and avoid injury to the saphenous nerve.

After flush ligation was performed, the stripper end was passed after a transverse venotomy was created in the GSV at or below the level of the knee according to the level of the incompetent segment. Stripping was done by a downward direction that is better for the avulsion of tributaries and diminish injury to saphenous nerve then stab avulsion and micro phelebectomy were done for any perforator or blow out. Skin incisions were closed, elastic stocking were immediately applied for one week, complete bed rest for 24 hours, and early ambulation was recommended.

\section{Group (II): (EVLA) Endovenous laser ablation}

Duplex ultrasonography was performed in the upright position to map incompetent sources of venous reflux and mark the skin overlying GSV starting at the SFJ. GSV diameter was measured in an upright position and recorded. The target extremity was sterilized and draped. The Patient was placed in an antitrendelenburg position to facilitate cannulation of GSV either directly or under ultrasound guidance. The site of puncture was few centimeters below the knee level with an 18-gauge cannula.

J-tip 0.035 inch guidewire was passed under ultrasound guidance up to the SFJ. A 5-F long introducer sheath was placed into the GSV over the guidewire. The introduced length of the sheath ranged from $36 \mathrm{~cm}$ to $50 \mathrm{~cm}$ depending on the length of GSV to be treated. The bare-tipped fiber $600-1 \mathrm{~m}$ diameter connected to a 980-nm diode laser was introduced through the sheath. The device was set with $10 \mathrm{~W}$ power and pulsed mode manner 10 seconds (on) and one second (off).

The distal tip of the laser fiber was positioned $2 \mathrm{~cm}$ below the SFJ under duplex sonographic guidance and confirmed by direct visualization of the red aiming beam of the laser fiber tip through the skin.

Peri-venous tumescent anesthesia was injected into the fascial space surrounding the GSV under cross-sectional sonographic guidance along its length. The amount of tumescent anesthetic solution was about $400-500 \mathrm{cc}$. The component of tumescent anesthesia was $20-25 \mathrm{ml}$ lidocaine $2 \%$ buffered with $1.4 \%$ sodium bicarbonate in $500 \mathrm{cc}$ saline $0.9 \%$. Then allowing the laser energy to be fired and then the laser fiber and sheath were slowly pullbacks till they reached one centimeter above the site of puncture to avoid skin burn.

Bandage compression was applied postoperatively for $24 \mathrm{~h}$ then patients were asked to wear full-thigh class II compression stockings $(30-40 \mathrm{mmHg}$ ) for one week.

\section{Group (III): Endovenous chemical ablation with Trendelenburg's operation (eCAT)}

Steps: While the patient in a supine position and after the targeted extremity was sterilized and draped, Trendelenburg's operation is done under local infiltration anesthesia(saphenofemoral disconnection (SFD) and ligation of all tributaries of GSV). Puncture of GSV just anterior to medial malleolus (MM) was done under local infiltration anesthesia.The guidewire is located to the vein lumen. The correct position of the sheath is controlled.

Introducing the wire from the distal part of the GSV at the medial malleolus till the groin, then the catheter was introduced over the wire, then the wire was removed, followed by withdrawal of the catheter $2 \mathrm{~cm}$ from the saphenous stump. Then GSV was closed under vision. Flush the catheter and the sheath by $15 \mathrm{ml}$ normal saline. Closure of the wound and a sterile dressing was applied. Pad of gauze was put all over the course of GSV. Crepe bandage and graduated compression are applied from foot to groin. Air foam 1:4 polidocanol to air ratio by volume, $0.5 \mathrm{ml}$ polidocanol at syringe $3 \mathrm{ml}+2 \mathrm{ml}$ air at syringe $3 \mathrm{ml}$ are making foam, and inject $2.5 \mathrm{ml}$ foam for every $15 \mathrm{~cm}$ length of GSV, withdrawal of the catheter at speed of $15 \mathrm{~cm} / \mathrm{min}$ for the complete distribution of foam to vein endothelium.

The Injection was repeated again during catheter withdrawal with maximum volume of $15 \mathrm{ml}$. at the limb till the removal of the catheter and the sheath. Complete bed rest for the first 6 hours postoperatively. Return to daily activity on the 2 nd day. The crepe bandage was left in place for one week.

\section{Post-operative follow up (for one year).}

Clinical follow up for subcutaneous hematoma, recurrence, ecchymosis, infection, skin ulceration, burn, nerve injury, skin pigmentation, and degree of healing of venous ulcer or persistent pain. Duplex ultrasound follows up for early and late postoperative complications (after one week, one month and then after one year) and GSV for (diameter, recanalization).

\section{Statistical analysis of data}

The collected data were organized, tabulated and statistically analyzed using statistical package for social sciences (SPSS) version 21 (SPSS Inc, Chicago, USA), running on IBM compatible computer. For qualitative data, frequency and percent distributions were calculated. For quantitative data, mean, standard deviation (SD), minimum and maximum were calculated.

\section{RESULTS}

This was a comparative study conducted on patients presented by the primary $\mathrm{VV}$ of $\mathrm{LL}$ that operated upon at AL-Azhar 
University hospital (New Damietta) during the period from November 2016 to December 2018.

The demographic data were presented in table (1).

\begin{tabular}{|l|c|c|c|}
\hline Parameters & Group(I) & Group(II) & Group(III) \\
\hline $\begin{array}{l}\text { Mean Age } \\
\text { (years) }\end{array}$ & 33.76 & 34.88 & 37.56 \\
\hline Male & $13(52 \%)$ & $16(64 \%)$ & $15(60 \%)$ \\
Female & $12(48 \%)$ & $9(36 \%)$ & $10(40 \%)$ \\
\hline Married & $20(80 \%)$ & $16(64 \%)$ & $15(60 \%)$ \\
Single & $5(20 \%)$ & $9(36 \%)$ & $10(40 \%)$ \\
\hline Standing & $24(96 \%)$ & $21(84 \%)$ & $17(68 \%)$ \\
Nonstanding & $1(4 \%)$ & $4(16 \%)$ & $8(32 \%)$ \\
\hline
\end{tabular}

Table 1: Demographic data of the studied cases

In the present study, 43 patients $(57.3 \%)$ suffered from disfigurement, 21 patients $(28.0 \%)$ suffered from leg ulcer and 11 (14.7\%) suffered from pain. There were 65 patients $(86.7 \%)$ with competent SPJ.

The GSV caliber was found to be $(11.95 \pm 3.27)$, and $(8.64 \pm 1.8)$ and $(9.11 \pm 2.9)$ in groups I, II , and III respectively with statistically significant difference between group I and II and also between group I and III . There was no statistically significant difference when group II was compared with group III.

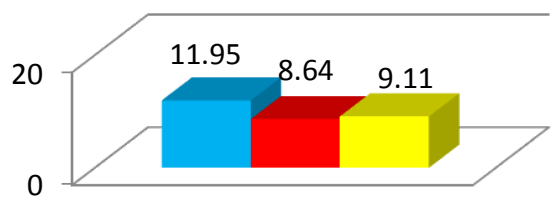

Group I Group II Group III

Figure 1: GSV Caliber $10 \mathrm{~cm}$ above Knee of the studied cases.

There were 47 patients $(62.7 \%)$ underwent the operation under spinal anesthesia, 5 (6.6\%) patients under general anesthesia, and $23(30.7 \%)$ patients under local anesthesia.

\begin{tabular}{|l|l|l|l|}
\cline { 2 - 4 } \multicolumn{1}{c|}{} & Group I & Group II & Group III \\
\hline $\begin{array}{l}\text { pain score (Mean } \\
\pm \text { SD) }\end{array}$ & $5.88 \pm 0.79$ & $3.15 \pm 0.73$ & $3.52 \pm 0.51$ \\
\hline
\end{tabular}

Table 2: Post-operative pain score

Post-operative complications was presented at table (3)

\begin{tabular}{|l|l|l|l|}
\cline { 2 - 4 } \multicolumn{1}{c|}{} & $\begin{array}{l}\text { Group I } \\
(\mathbf{n = 2 5})\end{array}$ & $\begin{array}{l}\text { Group II } \\
(\mathbf{n = 2 5})\end{array}$ & $\begin{array}{l}\text { GroupIII } \\
(\mathbf{n = 2 5})\end{array}$ \\
\hline Ecchymosis & $25(100 \%)$ & $5(20 \%)$ & $1(4 \%)$ \\
\hline Hematoma & $23(92 \%)$ & $1(4 \%)$ & $0(0.0 \%)$ \\
\hline Infection & $5(20 \%)$ & $0(0.0 \%)$ & $0(0.0 \%)$ \\
\hline Skin ulcer & $0(0.0 \%)$ & $2(8 \%)$ & $0(0.0 \%)$ \\
\hline
\end{tabular}

Table 3: Post-operative complications

Return to daily activity was found to be earlier for group II than for group III and group I as in table (5)Return to daily activity is more rapid significantly in patients treated with laser (group II) than group (I) or group (III)

\begin{tabular}{|l|c|c|c|}
\cline { 2 - 4 } \multicolumn{1}{c|}{} & Group I & Group II & Group III \\
\hline $\begin{array}{l}\text { Return to activity } \\
(\text { Mean } \pm \text { SD) }\end{array}$ & $10.71 \pm 2.56$ & $3.92 \pm 1.99$ & $4.68 \pm 1.67$ \\
\hline
\end{tabular}

Table 4: Duration till return to daily activity.

Residual varicosities had been detected in 10,15,5 cases for groups I, II, and III respectively. There were 5 cases $(20.0 \%)$ in the group I and 2 cases $(8.0 \%)$ in group II suffered from postoperative saphenous nerve injury. No saphenous nerve injury had been detected in patients of group III.

As regard postoperative residual varicosity, 10 cases $(40.0 \%)$ in group I, $15(60.0 \%)$ in group II and 5 cases $(20.0 \%)$ in group III suffered from post-operative residual varicosity. Also there were 4 cases $(16.0 \%)$ in group I and 4 cases $(16.0 \%)$ in group II suffered from recurrence after one year. Post-operative GSV Patency, recanalization and occlusion were presented in table (5)

\begin{tabular}{|c|c|c|c|c|}
\hline & & $\begin{array}{l}\text { Group I } \\
\text { (25) }\end{array}$ & $\begin{array}{l}\text { Group II } \\
\text { (25) }\end{array}$ & $\begin{array}{l}\text { Group } \\
\text { III (25) }\end{array}$ \\
\hline \multirow{4}{*}{$\begin{array}{l}\text { One } \\
\text { week }\end{array}$} & Removed & $\begin{array}{l}25 \\
(100 \%)\end{array}$ & $1(4 \%)$ & $0(0 \%)$ \\
\hline & Occluded & $\begin{array}{c}0 \\
(0.0 \%)\end{array}$ & $18(72 \%)$ & $\begin{array}{l}23 \\
(92 \%)\end{array}$ \\
\hline & $\begin{array}{l}\text { Partial } \\
\text { occluded }\end{array}$ & $\begin{array}{c}0 \\
(0.0 \%)\end{array}$ & $6(24 \%)$ & $\begin{array}{r}2 \\
(8 \%)\end{array}$ \\
\hline & Recanalized & $\begin{array}{c}0 \\
(0.0 \%)\end{array}$ & $0(0.0 \%)$ & $\begin{array}{c}0 \\
(0.0 \%)\end{array}$ \\
\hline \multirow{4}{*}{$\begin{array}{l}\text { Three } \\
\text { month }\end{array}$} & Removed & $\begin{array}{c}25 \\
(100 \%)\end{array}$ & $0(0.0 \%)$ & $\begin{array}{c}0 \\
(0.0 \%)\end{array}$ \\
\hline & Occluded & $\begin{array}{c}0 \\
(0.0 \%)\end{array}$ & $20(80 \%)$ & $\begin{array}{r}19( \\
76 \%)\end{array}$ \\
\hline & $\begin{array}{l}\text { Partial } \\
\text { occluded }\end{array}$ & $\begin{array}{c}0 \\
(0.0 \%)\end{array}$ & $5(20 \%)$ & $\begin{array}{c}6 \\
(24 \%)\end{array}$ \\
\hline & Recanalized & $0(0 \%)$ & $0(0.0 \%)$ & $0(0 \%)$ \\
\hline \multirow{4}{*}{$\begin{array}{l}\text { One } \\
\text { year }\end{array}$} & Removed & $19(76 \%)$ & $0(0 \%)$ & $0(0 \%)$ \\
\hline & Occluded & $0(0 \%)$ & $20(80 \%)$ & $\begin{array}{l}22(88 \\
\%)\end{array}$ \\
\hline & $\begin{array}{l}\text { Partial } \\
\text { occluded }\end{array}$ & $0(0 \%)$ & $5(20 \%)$ & $3(12 \%)$ \\
\hline & Recanalized & $6(24 \%)$ & $0(0.0 \%)$ & $0(0.0 \%)$ \\
\hline
\end{tabular}

Table 5: Post-operative GSV Patency at one week, 3 months and one year post-operatively.

\section{DISCUSSION}

For many years, surgery was considered the gold standard in the treatment of VV. Recently, less invasive procedures are more popular for the management of varicose veins(such as EVLA, RFA). Also, patients nowadays prefer less invasive procedures as a line of treatment as it is associated with rapid recovery \& return 
Agena et al. - Conventional, laser and chemical ablation of varicose veins to normal activity if compared with conventional procedures. Pronk et al ${ }^{7}$.

In this study, male predominance was remarkable as it represents about $58.7 \%$ of patients. This may be due to male persons stand longer time times and exert more effort.

In this study, the mean age was 35.4 in patients who underwent any intervention. In 2010, Christenson et $\mathrm{al}^{8}$, had published a study on 200 cases, one hundred cases in each group, and the mean age was 45 in the laser group and 46 in the patients underwent surgical ligation and stripping. Pronk8 published his study which was done on 130 patients and also had documented older mean age which was 50 years in the surgical group, and 49 years in the laser group.

All patients in our study were presented with pain, varicosities, or leg ulcer. 43 patients $(57.3 \%)$ suffered from varicosity, 21 patients $(28.0 \%)$ suffered from ulcer and $11(14.7 \%)$ suffered from pain.

Most of the recent studies mentioned similar presentations in their patients, Jan $\mathrm{T}$ and his colleges ${ }^{9}$ published their study in 2010, documented 200 limbs, all of them complained from pain, $89 \%$ of them suffered from heaviness. In 2008, Kalteis and his colleges ${ }^{11}$ published a study working on 95 patients, $61 \%$ and 75 $\%$.of patients in both laser and surgical groups respectively complained from heaviness. However, only4 \% of the laser group and $8 \%$.of the surgical group suffered from pain in their lower limbs.

There was not any significant difference in results regarding intraoperative complications in recent studies, and this was the same in our study as $90 \%$ in patients underwent surgical ligation of SFJ and $95 \%$ of patients underwent laser ablation and $99 \%$ of patients underwent eCAT did not document any intraoperative complications.

Unlike most of the studies, In the present study, Return to daily activity is more rapid significantly in patients treated with laser (group II)( 3.92 \pm 1.99 )days than group (I)( $10.71 \pm 2.56$ )days or group (III)( $4.68 \pm 1.67)$ days.

Return to normal activities after surgery is of great importance to patients. They usually care about the time needed to resume usual lifestyle they used to do before surgical intervention. Kalteis10 documented that patients underwent laser ablation needed less time to return to daily activities than patients who underwent surgical ligation of saphenofemoral.junction and stripping.

On the other hand, Pronk and his colleges ${ }^{7}$ had different result in their study published in 2010. They noticed that there was no significant difference between surgical intervention and laser ablation groups. Meantime needed to return to normal activity was 3.2 with SD 4 in patients underwent conventional surgery while it was 3.2 with SD 4.3 in patients group who underwent laser ablation Pronk et al ${ }^{7}$.

Jan, 9 also documented similar results between both groups which recorded mean time 6.6 days in group of patients who conventional surgery and 6.9 days in laser group. Almedia JI, Raines JK ${ }^{11}$ also showed no significant difference between both groups regarding the ambulation time with slight privilege in the laser ablation group.

According to our study, there was a significant difference between the three groups regarding the time needed for return to normal activity. In surgery groups the mean time was $(10.71 \pm 2.56)$ days, in the laser group, the meantime $(3.92 \pm 1.99)$ days. While in eCAT group the meantime was $(4.68 \pm 1.67)$ days.

This variation could be explained by variation of patient's socioeconomic levels, nature of their jobs and cultural factors because patients considered operations with surgical wound as a major surgery needs long time of rest and rehabilitation.

Similar to our results, Gloviczki ${ }^{12}$ reported that patients of laser ablation group returned back to their normal lifestyle 3 days earlier than patients of conventional surgery group.

As regard postoperative complications, in surgery group, there were 25 patients complained of ecchymosis along the course of GSV. 23 cases reported subcutaneous hematoma that varied from small collection to large hematoma, 5 cases of postoperative infection which were managed conservatively.

On the other hand, there was ecchymosis in 5 cases in the laser group. Two cases were complicated by ecchymosis at the puncture site, 2 cases of skin ulceration along the infra-genicular portion of GSV which might be due to insufficient tumescent injection and a very superficial segment of GSV. The two cases improved with conservative treatment. Two cases complained of edema and managed by elastic stocking. Only 2 cases suffered from DVT in the posterior tibial vein and popliteal vein and might be caused by patient factors such as obesity and delayed ambulation. This condition was improved with full anticoagulation. As regard eCAT 1 case suffered from subcutaneuos ecchymosis, no hematoma, infection, or skin ulceration.

Regarding postoperative pain, postoperative pain score decreased significantly in patients treated with laser (group II) $(3.15 \pm 0.73)$ and in patient treated with e CAT (group III) $(3.52 \pm 0.51)$ when compared with patient with surgery (group I) $(5.88 \pm 0.79)$ with statistical significant differences.

In 2012, Siribumrungwong and his colleagues ${ }^{13}$ reported that patients treated with surgical ligation of SFJ had higher rates of hematoma compared with those who were treated with laser ablation. Post-operative pain also was less sever in EVLA than surgical intervention. It is announced that wound infection is less in the laser ablation group by $60 \%$ if compared with the incidence of infection in patients who underwent surgical ligation of SFJ and stripping. This study also mentioned that EVLA had a lower incidence of hematoma formation and pain in day 0 to day 7 following procedures were less in the laser group.

Recurrence remains a significant problem after either endovenous laser ablation or triple saphenectomy. After surgical intervention, neovascularization.in the subcutaneous tissue around the SFJ can lead to recurrence De Medeiros ${ }^{14}$ The process of neovascularization may be associated with groin incision. The presence of non-competent tributaries after ligation is another possible cause for recurrence. In general, recurrence is caused.by a connection between the remaining segment of GSV and new vessels or incompetent tributaries Bush et $\mathrm{al}^{15}$.

In our study, follow up was done after 1 week, 1month, 12 months. This was done by clinical evaluation and the duplex US. There were significant differences between the three groups.

After 1 week, There were 18 cases $(72.0 \%)$ occluded and 6 cases (24\%) partially occluded in group II and 23 cases $(92.0 \%)$ occluded and $2(8.0 \%)$ partially occluded in group III postoperative GSV.

After three months there were 20 cases $(80.0 \%)$ occluded and 5 cases $(20.0 \%)$ partially occluded in group II and 19 cases (76.0\%) occluded and $6(24.0 \%)$ partially occluded in group III post-operative GSV.

After one year, duplex US was performed for all patients and in one year post-operative GSV there were 6 cases $(24.0 \%)$ revascularized in group I, 20 cases $(80.0 \%)$ occluded and 5 cases (20.0\%) with partially occluded in group II associated with 22 cases $(88.0 \%)$ occluded and 3 cases $(12.0 \%)$ partially occluded in group III. 
We agreed with Bush and colleagues15 that the most important factors associated with varicose veins recurrence included a new or recurrent perforator veins incompetence, recanalized GSV and reflux in anterior accessory great saphenous vein Bush et al. ${ }^{15}$

Recently published studies show similar results, that patients managed by EVLA had the same risk of recurrence as patients who underwent surgical ligation of SFJ and stripping. In a review presented by McBride16confirmed that endovenous techniques were as effective as standard surgery, but in most of comparative data presented EVLA was better regarding postoperative complications, pain and return to normal activity McBride ${ }^{16}$

This is can be explained by a study done by Kianfard and colleagues ${ }^{17}$, as they did not observe neovascularization in those patients who underwent laser ablation versus $12 \%$ in those who were managed by surgical stripping Kianfard et al. ${ }^{17}$ Other studies also reported that inguinal neovascularization is almost absent after endovenous procedures while it is very common after incisions in groin and dissection around GSV Pichot et al. ${ }^{18}$ but it is not evidence-based medicine in or opinion as there is no evidence that is a large huge number of veins which developed post-operatively is neovascularization but may be missed named or unnamed tributaries at SFJ(failure of flush disconnection).

We found that 5 patients in the surgical group were not satisfied with the results due to paraesthesia that lasts for relatively long time (5 cases)as result of saphenous nerve injury, and hematoma along the course of stripped GSV (most cases) and they seek for better cosmetic appearance. While there were 2 cases not satisfied with results in the laser group due to skin ulceration due to thermal burning. In 2004, Winterborn and his team, 20 documented that up to one -third of patients may remain unsatisfied in the long term after both surgical ligation and laser ablation.

\section{CONCLUSION}

For management of primary varicose veins of the lower limbs, endovenous chemical ablation with Trendelenburg's operation had better results than endovenous laser ablation and triple saphenectomy as regard lower incidence of postoperative ecchymosis and hematoma formation, saphenous nerve injury, residual varicosities and recurrence rate. However, endovenous Laser ablation is better as regard return to daily activity and no difference between surgery and eCAT as regard the incidence of post-operative skin ulceration due to thermal burning in EVLA group.

\section{REFERENCES}

1. Callam M.J. Epidemiology of varicose veins Br J Surg. 1994; 81: 167-73.

2. Rasmussen LH, Lawaetz M, Bjoem L, Vennits B, Blemings A, Eklof B. Randomized clinical trial comparing endovenous laser ablation, radiofrequency ablation, foam sclerotherapy and surgical stripping for great saphenous varicose veins. $\mathrm{Br}$ J Surg. 2011;98:1079-87.

3. Faluji N, Kianifard B, Holdstock JM and Whiteley MS ,: A novel endoluminal technique for varicose vein management: The VNUS Closure. Phlebology; 2015;16: 145 -148

4. Shepherd AC, Gohel MS, Brown LC, Metcalfe MJ, Hamish M, Davies AH. Randomized clinical trial of VNUS Closure FAST radiofrequency ablation versus laser for varicose veins. Br J Surg. 2010; 97:810-8.
5. Baccaglini JR, King T, Sahagal A and Vidimos AI : Varicose veins: newer better treatments are available. Cleveland Clinic Journal of medicine 2015; 72(4):312-328.

6. Cavezzi A and Frullini A :The role of sclerosing foam in ultrasound guided sclerotherapy of the saphenous veins and of recurrent varicose veins: our personal experience: Aust NZJ phlebol 2016; 3:49-50.

7. Pronk JM. And Moneta GL: Reporting standards in venous disease: an update. International consensus committee on chronic venous disease. J Vasc Surg 2010; 21(4):635-645.

8. Christenson:Varicose vein: a comparison of Surgery and compression of sclerotherapy. Lancet 2010; 2:1188.

9. Jant RS, Cadle I and Cross KS: Preoperative assessment of primary varicose veins: A duplex study of venous incompetence. Eur J Vasc Endo Vasc Surg 2001.; 21(4):370373.

10. Kalteies LS, Sadek M. Fiber type as compared to wavelength may contribute more to improving postoperative recovery following endovenous laser ablation, J Vasc Surg Venous Lymphat Disord. 2008; 4(3):286-292; 10.

11. Almedia JI, Raines JK : Radiofrequency and laser ablation in the treatment of varicose veins. Ann Vasc Surg 2006; 20:547552.

12. Gloviczki P, Comerota AJ, Dalsing MC, Eklof BG, Gillespie DL; et al, Society for Vascular Surgery, American Venous Forum. The care of patients with varicose veins and associated chronic venous diseases: clinical practice guidelines of the Society for Vascular Surgery and the American Venous Forum. J Vasc Surg. 2011;53:2S-48.

13. Siribumrungwong, Ceulen R, Nelemans $P$, et al. Randomized clinical trial of ultrasound-guided foam sclerotherapy versus surgery for the incompetent great saphenous vein. Br J Surg. 2012; 99:1062-

14. Demederios, Davies B , Harradine K, et al. :Stripping of the long saphenous vein reduce the rate of reoperation for recurrent Varicose veins: Five-year results of a randomized trial. J Vasc Surg 2006; 29:589-592.

15. Bush RG, Derrick M, Manjoney D: Major neurological events following foam sclerotherapy. Phlebology 2012; 23:189-92.

16. McBrid,Rautio T, et al. Endovenous obliteration versus conventional stripping operation in the treatment of primary varicose veins: a randomized controlled trial with comparison of the costs. J Vasc Surg. 2010; 35:958-965.

17. Kianford et al: Treatment of the incompetent great saphenous vein by endovenous radiofrequency powered segmental thermal ablation: first clinical experience. J Vasc Surg 2006 47:151-156.

18. Picot MR, Ruckley CV, Guex JJ, Vaughan C, De Palma RG, Royle P, Ekluf B and the REVAS Group: Recurrent varices after Surgery (REVAS), a consensus document. Cardio Vascular Surgery 2004; 8(4): 233 -245.

19. Winterborn RJ, Foy C and Earnshaw JJ : Causes of varicose vein recurrence: Late results of a randomized controlled trial of stripping the long saphenous vein. J Vasc Surg, 2004;40:312-319. 